aspiran sus promotores. Pueden atestiguarlo, en primer término, las cuatro colaboraciones académicas incorporadas a la sección de artículos, que se dedican a temas de especial relevancia: la nueva configuración del Derecho de familia (J. A.García Amado), la autonomía municipal (J. M. Goig y M. A. Núñez), las fuentes de legitimación del poder en la sociedad democrática (J. A. Moreno Fernández) y la diversidad de sistemas penitenciarios (J. A. Serrano Patiño); estudios que, por lo demás, van acompañadas de una extensa y cuidada presentación de los ya mencionados Anales de la Universidad de Oviedo en su primera época, hasta el año 1950 (a cargo de M. Friera Álvarez). Y puede acreditarlo también el contenido de la sección dedicada a «Diálogos y Entrevistas», que desde luego hace honor a este preciso enunciado: por un lado, contiene un intenso e ilu- sionado diálogo, de lectura muy recomendable, entre los profesores Atienza y García Amado acerca de la clásica distinción, dentro de la Filosofía del Derecho, entre Derecho Natural y Positivismo Jurídico; por otro, aporta sendas entrevistas al magistrado Perfecto Andrés Ibáñez y al profesor universitario Juan José Gil Cremades, ambas muy sugerentes para la reflexión jurídica y muy útiles, por cierto, para el conocimiento de nuestro sistema político, social y universitario. Nuestra mejor enhorabuena para la Facultad de Derecho de la Universidad de Oviedo y para quienes han participado, desde uno u otro frente, en esta singular iniciativa. La Universidad española, como principal destinataria de la misma, quedará sin duda agradecida.

Joaquín GarCía MurCia Departamento de Derecho del Trabajo y de la Seguridad Social Facultad de Derecho de la UCM

\title{
Anuario 2015 de la Academia Iberoamericana de Derecho del Trabajo y de la Seguridad Social.
}

En los primeros meses de 2016 ha visto la luz el Anuario 2015 de la Academia Iberoamericana de Derecho del Trabajo y de la Seguridad Social, dedicado a «La legislación laboral iberoamericana en el siglo XXI» y coordinado por el Presidente de la citada Academia, el abogado y profesor venezolano Óscar Hernández Álvarez. Continúa esta publicación la serie iniciada el año anterior con el Anuario 2014, que estuvo dedicado a los procesos de reforma laboral en los principales países de Iberoamérica. El Anuario correspondiente a 2015 


\section{Recensiones}

incluye dieciocho colaboraciones, que en su mayor parte dan cuenta de los acontecimientos legales más importantes que en el ámbito de las relaciones de trabajo y la protección social han tenido lugar en los países iberoamericanos, aunque algunos de estos estudios tienen carácter más monográfico y se extralimitan de forma deliberada de los contornos trazados con carácter general para la obra, como ocurre con el que se dedica a la lucha contra la discriminación en el ámbito de la Unión Europea o con el que reflexiona sobre el principio de autonomía y el Derecho del Trabajo.

Con esas salvedades, y como era de esperar a la vista de su título, las colaboraciones reunidas en este Anuario tratan de dar un semblante lo más preciso posible de las vicisitudes sufridas por el ordenamiento laboral y social en esta década y media del siglo XXI en esos distintos países. A buena parte de las colaboraciones se les ha dado un marcado tono general, en cuanto han querido dar cuenta no sólo de datos normativos concretos sino también de tendencias y líneas de regulación (como es el caso, sobre todo, de las que se refieren a Bolivia, México, Uruguay, Cuba o Perú). Otras cola- boraciones, sin embargo, se centran más bien en los cambios normativos de los años más recientes, ya sea el bienio 2014-2015 (como es el caso de Chile, España, Panamá o Venezuela), ya sea estrictamente el año 2015 (como sucede en los casos de Argentina, Brasil y diversos países de Centroamérica), bajo el presupuesto, seguramente, de que la reseña de los procesos de reforma laboral incorporada al Anuario de 2014 era suficiente para tomar conciencia de esa otra dimensión más retrospectiva. Por lo común, las colaboraciones abordan en términos globales lo acaecido en el ordenamiento laboral, pero en algún caso la reseña normativa se ciñe a determinadas parcelas del sistema, como sucede con la aportación relativa a Colombia, que se limita al tratamiento normativo de los derechos de asociación y de huelga. Por lo demás, la mayor parte de los estudios abordan conjuntamente el Derecho del Trabajo y la Seguridad Social, aunque el Anuario incluye también alguna aportación específica sobre esta última materia (referida concretamente a Venezuela).
Joaquín García Murcia
Departamento de Derecho
del Trabajo y de la Seguridad Social
Facultad de Derecho de la UCM 